\title{
Infrared Spectra of the Hydrated Borates
}

\author{
C. E. Weir \\ Institute for Materials Research, National Bureau of Standards, Washington, D.C.
}

(November 4, 1965)

\begin{abstract}
Infrared absorption spectra of 42 different hydrated borates were obtained in the $2000-300 \mathrm{~cm}^{-1}$ range. A few spectra were obtained between 4000 and $2000 \mathrm{~cm}^{-1}$. Most spectra are complex and cannot be interpreted satisfactorily except in the case of the simplest anions. Many correlations between spectra are possible, however, and possible anion types have been deduced. Differentiation between triangular and tetrahedral boron is possible on the basis of the spectra but is less certain than in the case of the anhydrous borates.
\end{abstract}

Key Words: Hydrated borates, infrared spectra, absorption spectra, borates, boron coordination, borate anions

\section{Introduction}

A comprehensive survey of the infrared spectra of the crystalline anhydrous inorganic borates was reported recently [1]. ${ }^{1}$ The spectra were correlated with known structures and predictions of unknown structures were made on the basis of the observed spectra. Two of the predicted anion structures have been verified by subsequent $\mathrm{x}$-ray crystallographic studies $[2,3]$. The obvious extension of the studies to include the hydrated borates is the subject of this report.

The hydrated borates have been subjected to a more systematic study than the anhydrous materials, largely as a consequence of their mineralogical occurrence. Miller and Wilkins [4] reported data on eight hydrated borates obtained by the mull technique. Several years later, Takeuchi [5] studied the spectra of 17 borates of which 12 were hydrated. Takeuchi also used the mull technique of sample preparation. Moenke and his coworkers, in a series of papers, [6-13] have presented spectra obtained on approximately 17 hydrated borates using the $\mathrm{KBr}$ pellet technique. Akhamanova [14] has reported on seven hydrated borates and Plyusnina and Kharitonov [15] have studied six, with spectra in both cases being obtained using films deposited from isopropyl alcohol on alkali halide plates. The early work by Miller and Wilkins [4] and that of Takeuchi [5] had a lower frequency limit of about $600 \mathrm{~cm}^{-1}$ which is too high to obtain some of the known fundamental vibrations of the borate anion. All the more recent studies, however, extend as far as $400 \mathrm{~cm}^{-1}$.

${ }^{1}$ Figures in brackets indicate the literature references at the end of this paper.
In the present study, infrared spectra were obtained for 42 different hydrated borates. Most specimens were natural minerals but in many instances synthetic materials were also available. Approximately 63 different specimens were studied so that it was possible to determine the reproducibility of the spectra for materials of different origin - a question of importance for natural minerals which may contain infrared active impurities.

\section{Experimental Method and Apparatus}

Experimental techniques and equipment were similar to those described previously for the anhydrous borates [1]. A double-beam grating spectrometer was used to cover the range $4000-200 \mathrm{~cm}^{-1}$. This range was covered in two steps, $4000-400 \mathrm{~cm}^{-1}$ and 2000-200 $\mathrm{cm}^{-1}$. In each case the lower frequency limit imposed by the available energy was higher than the limits given. Most spectra were obtained only in the range $2000-300 \mathrm{~cm}^{-1}$ because the fundamentals of the borate anions were known to occur in this range. For these studies powdered films deposited on CsBr plates from a volatile liquid were used. A few spectra in the higher frequency range were obtained to locate the $\mathrm{OH}$ fundamental stretching modes. For these studies the spectra were obtained using a mull with perfluorokerosene as the suspending medium. In both cases a blank cell was placed in the reference beam of the spectrometer. The possibility of dehydrating the specimens precluded using dry air in the instrument and considerable care was exercised in the $500-300 \mathrm{~cm}^{-1}$. region. In this range only those bands were considered to originate in the specimen which were not obtained on a comparison spectrum run with no specimen in the beam. 


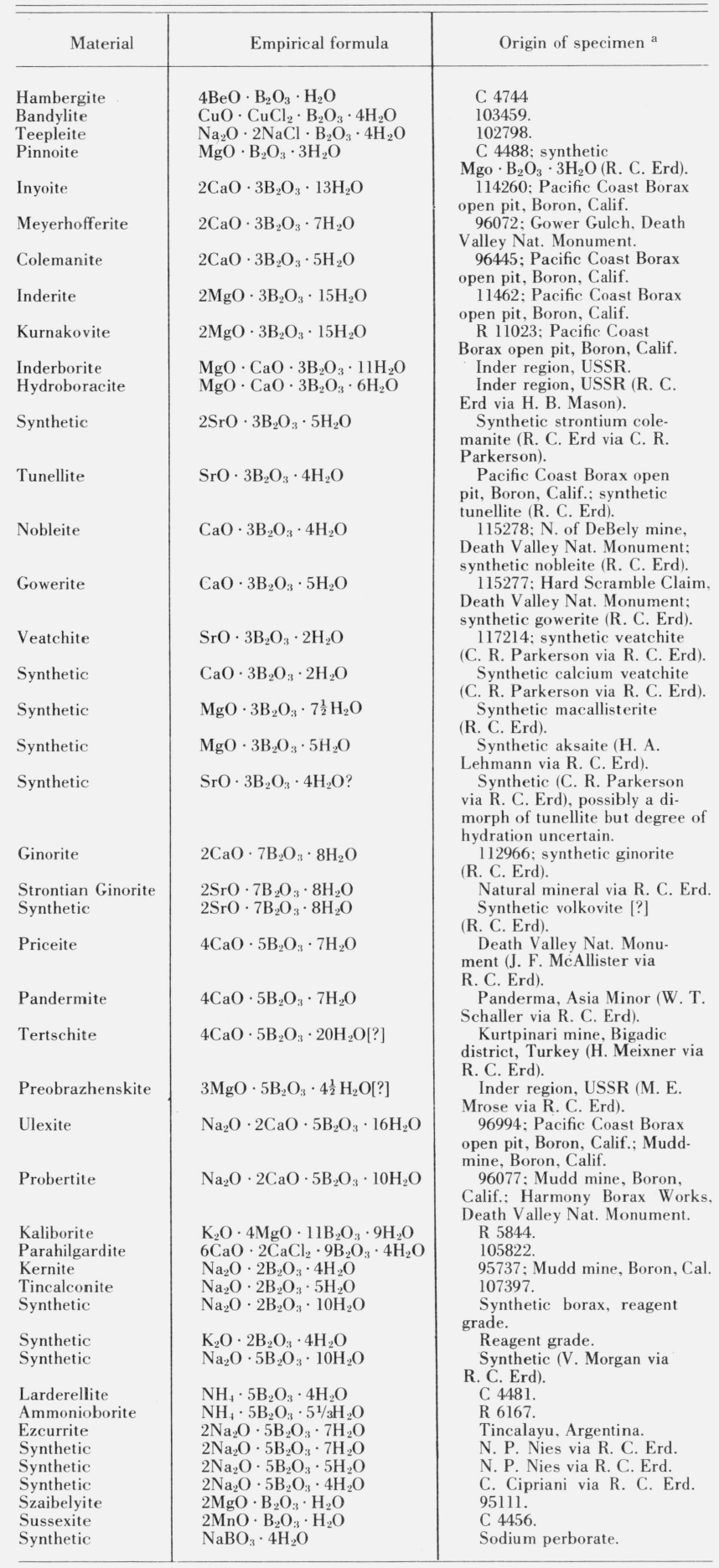

a Number of specimens studied is equal to the number of listings for each material separated by semicolons. Numerals represent catalog numbers in the mineral collection of the Smithsonian Institution.
The samples studied are listed in table l. Column 1 of this table lists the mineral or chemical name, column 2, the empirical formula, and column 3, the source of the material. Throughout this paper, samples will be referred to by the mineral names and synthetic samples will be designated by their composition unless it is known that the synthetic and natural minerals are equivalent. In the latter case the mineral name will be used. Samples were obtained generally from two sources, the mineralogical collection of the Smithsonian Institution and the U.S. Geological Survey. In column 3, designations denoted by numbers correspond to catalog numbers in the Smithsonian collection. Origins of specimens obtained from the U.S. Geological Survey are listed in column 3. The total number of samples of each mineral type studied is indicated by the number of listings in column 3 separated by semicolons. The order in which the samples are listed in table 1 corresponds to the order followed in the discussion.

\section{Results and Discussion}

\subsection{Presentation of Data}

Data will be presented here as in the previous report [1]. Compounds are grouped according to the anion type expected based on the ideas presented by Christ [16]. For each compound, observed bands are tabulated with the type of band designated by the usual abbreviations. ${ }^{2}$ Typical spectra are shown only for a few of the materials and only for the range 1800 $\mathrm{cm}^{-1}$ to approximately $300 \mathrm{~cm}^{-1}$.

\subsection{Borates With Simple Anions}

In order to assess the extent to which analyses of the spectra of the hydrated borates can be pursued, it is instructive to consider first the spectra of hambergite, bandylite, teepleite, and pinnoite. These materials have known structures with relatively simple anions. Hambergite contains unhydrated planar $\mathrm{BO}_{3}^{-3}$ groups $[17,18]$ and the formula $\mathrm{Be}_{2}(\mathrm{OH}) \mathrm{BO}_{3}$ represents the structure. Both bandylite and teepleite contain isolated $\mathrm{B}(\mathrm{OH})_{4}^{-1}$ groups and their structures may be represented by the formulas $\mathrm{CuB}(\mathrm{OH})_{4} \mathrm{Cl}$ and $\mathrm{Na}_{2} \mathrm{~B}(\mathrm{OH})_{4} \mathrm{Cl}$ respectively $[19,20,21]$. Pinnoite contains anions of the form $\left[\mathrm{B}(\mathrm{OH})_{3} \mathrm{OB}(\mathrm{OH})_{3}\right]^{-2}$ which can be considered as resulting from condensing two $\mathrm{B}(\mathrm{OH})_{4}^{-1}$ groups with the elimination of $\mathrm{H}_{2} \mathrm{O}$ [22]. It is of interest to compare the spectra of these substances with those obtained in previous studies of the anhydrous borates [1] where it was found that boron in 
three-fold coordination could be differentiated by the strong absorption derived from $\nu_{3}$ of the isolated ions which generally persisted in the complex anion. It was found that triangular boron even in complex anions exhibited broad strong absorption in the region $1100-1300 \mathrm{~cm}^{-1}$ and tetrahedral boron in the region $800-1100 \mathrm{~cm}^{-1}$. The $\nu_{2}$ and $\nu_{4}$ region $\left(600-800 \mathrm{~cm}^{-1}\right)$ of the isolated ions also was found useful for differentiating these anion types provided isotope substitution was possible (see ref. 1; figs. 1, 2, 19, and p. 486).

The validity of these conclusions with respect to the hydrated borates can be evaluated by considering the spectra of the hydrates with simple anions shown in figure 1 and the absorption bands listed in table 2 . In hambergite the strong band at $1300 \mathrm{~cm}^{-1}$ can be ascribed to $\nu_{3}$ and the strong broad band centered at $750 \mathrm{~cm}^{-1}$ probably arises from $\mathrm{Be}-\mathrm{O}$ vibrations. The 600 and $650 \mathrm{~cm}^{-1}$ bands superimposed on the $\mathrm{Be}-\mathrm{O}$ band are probably the two components of $\nu_{4}$, and $\nu_{2}$ is probably obscured by the $\mathrm{Be}-\mathrm{O}$ band. The $1155 \mathrm{~cm}^{-1}$ band is unexpected. It does not seem strong enough for a $\nu_{3}$ band and it is tentatively considered to be a bending mode involving $\mathrm{BeOH}$.

In teepleite and bandylite the $\nu_{3}$ bands are ascribed to the strong bands between 900 and $950 \mathrm{~cm}^{-1}$. The somewhat weaker band at $845 \mathrm{~cm}^{-1}$ in teepleite may arise from a second component of $\nu_{3}$ or from $\nu_{1}$. In both materials the strong bands at lower frequencies may be due to $\nu_{4}$ or to an $\mathrm{OH}$ torsional mode. In teepleite the bands at 1170 and $1302 \mathrm{~cm}^{-1}$ are quite strong and might be erroneously considered to be $\nu_{3}$ fundamentals of triangular borate ions. In this spectrum they are weaker than the $\nu_{3}$ for the tetrahedral borate group and there is no danger of misinterpretation. These bands may represent either combinations or $\mathrm{B}-\mathrm{OH}$ bending modes. In bandylite the $1255 \mathrm{~cm}^{-1}$ band is no weaker than the $\nu_{3}$ band and misinterpretation is possible. From spectral studies on orthoboric acid, however, it seems that this band most probably arises from an $\mathrm{OH}$ distortion vibration [23].

In the pinnoite spectrum the strong broad bands in the $800-1000 \mathrm{~cm}^{-1}$ range are the most prominent features of the spectrum and presumably are derived from the antisymmetrical vibration, $\nu_{3}$, of the tetrahedral units. The complex series of bands below $800 \mathrm{~cm}^{-1}$ are probably derived from the original $\nu_{2}$ and $\nu_{4}$ vibrations. The region above $1100 \mathrm{~cm}^{-1}$ contains three broad strong bands which are somewhat weaker than the antisymmetrical bands and are probably the result of $\mathrm{B}-\mathrm{OH}$ distortion modes. These bands might easily be assumed to arise from triangular boron in a material with an unknown anion and show that interpretations must be made with great caution.

On the basis of these spectra it must be concluded that hydration of the borate anions produces spectra which cannot be interpreted readily from a knowledge of the spectra of the corresponding anhydrous anion. Hydration appears to produce absorption bands, some of which are very strong, throughout the spectra range

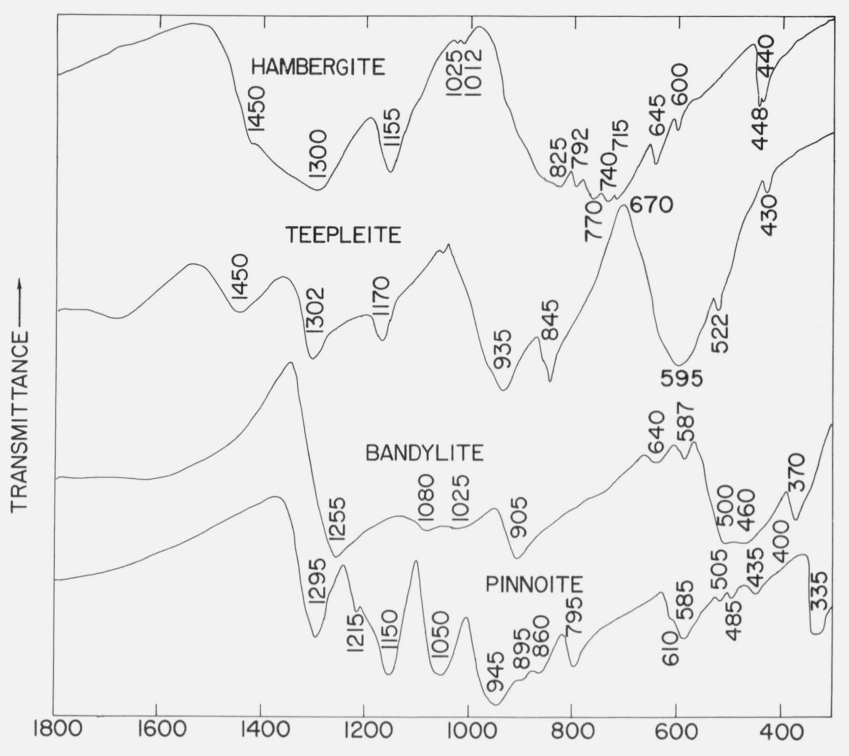

FIGURE 1. Infrared absorption spectra of hydrated borates containing simple anions.

TABLE 2. Infrared absorption spectra of borates with simple anions

\begin{tabular}{l|l|l|l}
\hline \hline & Pinnoite & Teepleite & Bandylite \\
\hline Hambergite & & & \\
& $3560 \mathrm{~s}$ & $3530 \mathrm{~s}$ & $3480 \mathrm{~s}$ \\
& $3400 \mathrm{sb}$ & $3400-2500 \mathrm{sb}$ & $3440 \mathrm{sbsh}$ \\
& $3140 \mathrm{svb}$ & $1450 \mathrm{mvb}$ & $2400 \mathrm{sb}$ \\
$1450 \mathrm{ssh}$ & $2930 \mathrm{vb}$ & $1302 \mathrm{sb}$ & $1255 \mathrm{svb}$ \\
$1300 \mathrm{vsvb}$ & $1295 \mathrm{sb}$ & $1170 \mathrm{~s}$ & $1080 \mathrm{mvb}$ \\
$1155 \mathrm{~s}$ & $1215 \mathrm{mb}$ & $935 \mathrm{vsb}$ & $1025 \mathrm{mvb}$ \\
$1025 \mathrm{w}$ & $1150 \mathrm{sb}$ & $845 \mathrm{vs}$ & $905 \mathrm{svb}$ \\
$1012 \mathrm{w}$ & $1050 \mathrm{svb}$ & $670 \mathrm{sh}$ & $640 \mathrm{w}$ \\
& $945 \mathrm{svb}$ & $595 \mathrm{svb}$ & $587 \mathrm{w}$ \\
$825 \mathrm{sb}$ & $895 \mathrm{msh}$ & $522 \mathrm{w}$ & $500 \mathrm{svb}$ \\
$792 \mathrm{~s}$ & $860 \mathrm{sb}$ & $430 \mathrm{w}$ & $460 \mathrm{svb}$ \\
$770 \mathrm{~s}$ & $795 \mathrm{sb}$ & & $370 \mathrm{~m}$ \\
$740 \mathrm{~s}$ & & & \\
$715 \mathrm{~s}$ & $610 \mathrm{wsh}$ & & \\
$645 \mathrm{~m}$ & $585 \mathrm{mb}$ & & \\
$600 \mathrm{~m}$ & $505 \mathrm{w}$ & & \\
$448 \mathrm{~m}$ & $485 \mathrm{~m}$ & & \\
$440 \mathrm{~m}$ & $435 \mathrm{mb}$ & & \\
& $400 \mathrm{~m}$ & & \\
& $335 \mathrm{~m}$ & & \\
& $310 \mathrm{~m}$ & & \\
& & &
\end{tabular}

studied. Bands apparently derived from $\nu_{3}$ modes of the anhydrous $\mathrm{BO}_{3}^{-3}$ and $\mathrm{BO}_{4}^{-5}$ groups still appear in the spectra of the hydrated anions. These bands are very strong and occur in the expected positions, i.e., 800-1100 $\mathrm{cm}^{-1}$ for tetrahedral boron and above 1100 $\mathrm{cm}^{-1}$ for triangular boron. However, strong bands apparently originating from $\mathrm{B}-\mathrm{OH}$ distortion modes complicate the spectra, particularly in the region $1100-1400 \mathrm{~cm}^{-1}$.

Data on teepleite have been obtained by Plyusnina and Kharitonov [15]. In gross features the spectra agree reasonably well but there are significant differences. For example, they do not report the 1450 or $430 \mathrm{~cm}^{-1}$ bands at all and band positions vary up to $21 \mathrm{~cm}^{-1}$ for the $845 \mathrm{~cm}^{-1}$ band which they found 
at $866 \mathrm{~cm}^{-1}$. The spectrum of pinnoite has been reported by Takeuchi [5] with considerable disagreement in the data. Comparison of the various spectra shows that there are considerable discrepancies in numbers of bands, band locations, and band contours.

\section{Divalent Metal Borates}

\subsection{The $\mathrm{MeO} \cdot 3 \mathrm{~B}_{2} \mathrm{O}_{3} \cdot x \mathrm{H}_{2} \mathrm{O}$ Compounds}

The family of divalent metal borates of general formula $2 \mathrm{MeO} \cdot 3 \mathrm{~B}_{2} \mathrm{O}_{3} \cdot x \mathrm{H}_{2} \mathrm{O}$ comprise the minerals inyoite, meyerhofferite, colemanite, fabianite, inderite, kurnakovite, inderborite, and hydroboracite. Except for fabianite $(2 \cdot 3 \cdot 1)$ all of these minerals, as well as a synthetic strontium $(2 \cdot 3 \cdot 5)$ analog of colemanite were examined during the present study. The infrared spectrum for fabianite has been reported by Kuhn and Moenke [13]. Among the other $2 \cdot 3 \cdot x$ compounds crystal structures have been determined for the following: Inyoite [25], meyerhofferite [26], colemanite [27], inderite [28, 29], and hydroboracite [30]. These borates all contain similar anions built up from sixmembered rings formed from alternate boron and oxygen atoms by corner sharing among two $\mathrm{BO}_{4}$ tetrahedra and one $\mathrm{BO}_{3}$ triangle. The oxygen atoms not shared by two boron atoms attach a hydrogen to form hydroxyl groups [16]. Isolated anions, $\left[\mathrm{B}_{3} \mathrm{O}_{3} \cdot(\mathrm{OH})_{5}\right]^{-2}$ are found in inyoite, meyerhofferite and inderite. In colemanite and hydroboracite, similar anions polymerize into chains having the formula $\left[\mathrm{B}_{3} \mathrm{O}_{4}(\mathrm{OH})_{3}\right]_{n}^{-2 n}$.

Typical spectra for some of these materials are shown in figure 2 and the observed absorption bands are listed in table 3 . As seen in figure 2, the spectra are very complex and more than a cursory interpretation is not possible. The spectra of inyoite and meyer-

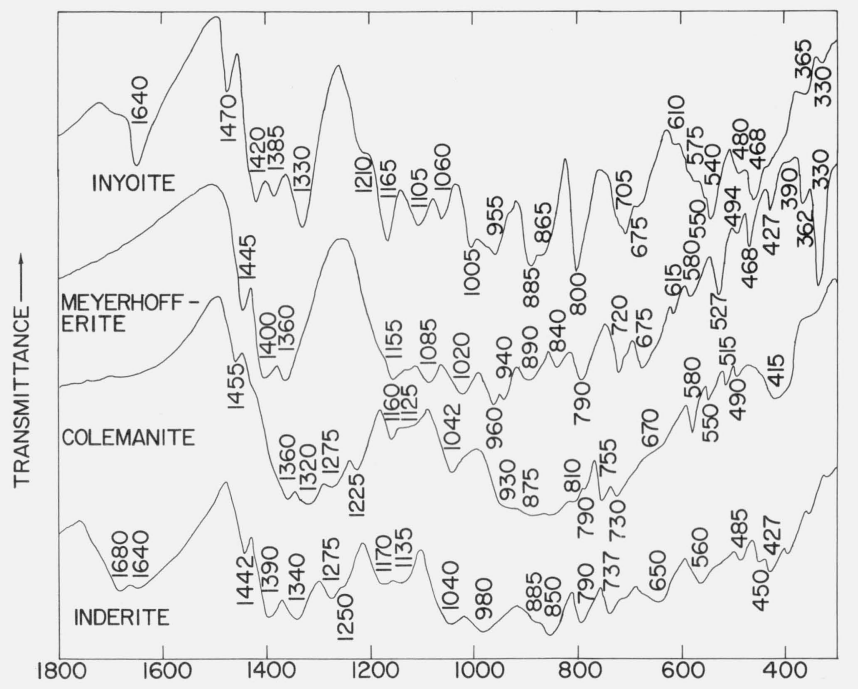

FiguRE 2. Infrared absorption spectra of $2 \mathrm{MeO}^{-} 3 \mathrm{~B}_{2} \mathrm{O}_{3} \cdot \mathrm{XH}_{2} \mathrm{O}$ compounds. hofferite are very similar with the predominant features being a strong complex absorption band near $1400 \mathrm{~cm}^{-1}$ and a similar band below $1200 \mathrm{~cm}^{-1}$. The former band probably is the counterpart of the antisymmetric mode for the triangular boron atoms and the latter band for the tetrahedral boron groups.

TABLE 3. Infrared absorption spectra of $2 \mathrm{MeO} \cdot 3 \mathrm{~B}_{2} \mathrm{O}_{3} \cdot \mathrm{XH}_{2} \mathrm{O}$ compounds

\begin{tabular}{|c|c|c|c|}
\hline Inyoite & Kurnakovite & Inderite & Inderborite \\
\hline $\begin{array}{l}3530 \mathrm{~s} \\
3440 \mathrm{~s} \\
3200 \mathrm{vsvb}\end{array}$ & $\begin{array}{l}3550 \mathrm{~m} \\
3450 \mathrm{~s} \\
3200 \mathrm{vsvb}\end{array}$ & & \\
\hline $\begin{array}{l}1640 \mathrm{mb} \\
1470 \mathrm{msh} \\
1420 \mathrm{~s} \\
1385 \mathrm{~s} \\
1330 \mathrm{~s} \\
1210 \mathrm{msh} \\
1165 \mathrm{~s} \\
1105 \mathrm{sb} \\
1060 \mathrm{~s} \\
1005 \mathrm{~s} \\
955 \mathrm{sb} \\
885 \mathrm{sb} \\
865 \mathrm{sb} \\
800 \mathrm{~s} \\
705 \mathrm{sb} \\
675 \mathrm{msh} \\
610 \mathrm{w} \\
575 \mathrm{msh} \\
550 \mathrm{w} \\
540 \mathrm{~m} \\
480 \mathrm{msh} \\
468 \mathrm{~s} \\
365 \mathrm{~m} \\
330 \mathrm{w}\end{array}$ & $\begin{array}{l}1650 \mathrm{mvb} \\
1450 \mathrm{msh} \\
1400 \mathrm{sb} \\
1390 \mathrm{~s} \\
1347 \mathrm{sb} \\
1257 \mathrm{~s} \\
1215 \mathrm{~s} \\
1160 \mathrm{~m} \\
1080 \mathrm{msh} \\
1045 \mathrm{msh} \\
1010 \mathrm{sb} \\
987 \mathrm{sb} \\
860 \mathrm{svb} \\
807 \mathrm{~s} \\
735 \mathrm{~m} \\
710 \mathrm{~m} \\
650 \mathrm{mb} \\
\end{array}$ & $\begin{array}{l}1680 \mathrm{mb} \\
1640 \mathrm{mb} \\
1442 \mathrm{msh} \\
1390 \mathrm{sb} \\
1340 \mathrm{sb} \\
1275 \mathrm{~s} \\
1250 \mathrm{msh} \\
1170 \mathrm{mb} \\
1135 \mathrm{mb} \\
1040 \mathrm{~s} \\
980 \mathrm{svb} \\
885 \mathrm{msh} \\
850 \mathrm{sb} \\
790 \mathrm{~m} \\
737 \mathrm{~m} \\
650 \mathrm{mvb} \\
\\
560 \mathrm{~m} \\
\\
485 \mathrm{~m} \\
450 \mathrm{~m} \\
427 \mathrm{~s} \\
325 \mathrm{mb}\end{array}$ & $\begin{array}{l}1660 \mathrm{mvb} \\
1460 \mathrm{msh} \\
1410 \mathrm{sb} \\
1390 \mathrm{msh} \\
1340 \mathrm{sb} \\
1290 \mathrm{msh} \\
1200 \mathrm{sb} \\
1150 \mathrm{wsh} \\
1065 \mathrm{~s} \\
1020 \mathrm{msh} \\
960 \mathrm{sb} \\
860 \mathrm{sb} \\
810 \mathrm{~m} \\
755 \mathrm{~m} \\
715 \mathrm{mvb} \\
650 \mathrm{mbsh}\end{array}$ \\
\hline
\end{tabular}

TABLE 3. Infrared absorption spectra of $2 \mathrm{MeO} \cdot 3 \mathrm{~B}_{2} \mathrm{O}_{3} \cdot \mathrm{XH}_{2} \mathrm{O}$ compounds-Continued

\begin{tabular}{|c|c|c|c|}
\hline Colemanite & Sr Colemanite & Hydroboracite & Meyerhofferite \\
\hline $\begin{array}{l}3130 \mathrm{svb} \\
1455 \mathrm{msh} \\
1360 \mathrm{sb} \\
1320 \mathrm{sb} \\
1275 \mathrm{sb} \\
1225 \mathrm{~s} \\
1160 \mathrm{mb} \\
1125 \mathrm{mvb} \\
1042 \mathrm{~s} \\
\\
930 \mathrm{svb} \\
875 \mathrm{svb} \\
810 \mathrm{msh} \\
790 \mathrm{msh} \\
755 \mathrm{~s} \\
730 \mathrm{~s} \\
670 \mathrm{w} \\
580 \mathrm{~m} \\
550 \mathrm{~m} \\
515 \mathrm{~m} \\
490 \mathrm{w}\end{array}$ & $\begin{array}{l}1450 \mathrm{msh} \\
1350 \mathrm{sb} \\
1300 \mathrm{sb} \\
1260 \mathrm{sb} \\
1190 \mathrm{mb} \\
1150 \mathrm{mb} \\
1060 \mathrm{msh} \\
1030 \mathrm{mb} \\
\\
925 \mathrm{~b} \\
865 \mathrm{sb} \\
790 \mathrm{msh} \\
750 \mathrm{~s} \\
730 \mathrm{~m} \\
710 \mathrm{msh} \\
575 \mathrm{~m} \\
545 \mathrm{w} \\
510 \mathrm{w} \\
490 \mathrm{w} \\
435 \mathrm{w} \\
\\
330 \mathrm{sb}\end{array}$ & $\begin{array}{l}1365 \mathrm{sb} \\
1300 \mathrm{~s} \\
1280 \mathrm{~s} \\
1188 \mathrm{~s} \\
1130 \mathrm{mb} \\
1080 \mathrm{sb} \\
1050 \mathrm{mb} \\
985 \mathrm{mbsh} \\
950 \mathrm{sb} \\
882 \mathrm{~s} \\
835 \mathrm{~s} \\
800 \mathrm{msh} \\
760 \mathrm{~s} \\
\\
580 \mathrm{~m} \\
550 \mathrm{w} \\
530 \mathrm{w} \\
505 \mathrm{w} \\
470 \mathrm{~m} \\
435 \mathrm{w} \\
425 \mathrm{w} \\
410 \mathrm{w} \\
\\
310 \mathrm{sb}\end{array}$ & $\begin{array}{c}1155 \mathrm{sb} \\
1085 \mathrm{sb} \\
1020 \mathrm{sb} \\
960 \mathrm{sb} \\
940 \mathrm{sb} \\
890 \mathrm{mb} \\
840 \mathrm{mb} \\
790 \mathrm{sb} \\
720 \mathrm{~s} \\
675 \mathrm{~m} \\
615 \mathrm{w} \\
580 \mathrm{~m} \\
527 \mathrm{~m} \\
494 \mathrm{w} \\
468 \mathrm{~s} \\
427 \mathrm{~m} \\
390 \mathrm{w} \\
362 \mathrm{~m} \\
330 \mathrm{~s}\end{array}$ \\
\hline
\end{tabular}


Aside from the gross similarity it is not possible to correlate the spectra band for band because there appear to be noticeable shifts of bands between the two spectra. These shifts are probably to be attributed to differences in hydrogen bonding largely produced by water molecules in the two structures, the formula of inyoite having $4 \mathrm{H}_{2} \mathrm{O}$ whereas that of meyerhofferite has only one $\mathrm{H}_{2} \mathrm{O}$ (table 1). The noticeable effects throughout the spectral range produced by this water are the main deterrent to a more detailed analysis of these spectra. The effect of polymerization on the isolated anions to form the chains in colemanite and hydroboracite can be determined by comparing their spectra with those of inyoite and meyerhofferite. The bands in colemanite and hydroboracite are broader and apparently more complex. In addition, there is a considerable apparent shifting of bands as might be expected from loss of hydrogen bonding water and coupling of the anions. The spectrum of colemanite gives a clear indication that the stretching vibrations involving the triangular boron atoms are represented by the band complex near 1300 $\mathrm{cm}^{-1}$. In the spectra of inyoite and meyerhofferite the strong bands, just below $1200 \mathrm{~cm}^{-1}$ might have been considered part of the antisymmetric stretch of the triangular borons. The fact that these bands become much weaker in colemanite which contains fewer $\mathrm{B}-\mathrm{OH}$ bonds implies that these bands may arise from $\mathrm{B}-\mathrm{OH}$ bending modes which might be expected in this frequency range [23]. It should be noted, however, that the spectrum of fabianite reported by Kühn and Moenke [13] appears to contradict the present conclusions, because it exhibits a strong band near $1142 \mathrm{~cm}^{-1}$.

Inderite and kurnakovite are polymorphs and their spectra correspond very closely as shown by the tabulated bands. Inderborite, a mixed calciummagnesium compound, also shows a spectrum similar to both the magnesium and the calcium compounds. The gross features of the spectra of the various magnesium and calcium compounds are also similar, but there are many differences in band positions and intensities.

Data on all of these materials, except the synthetic compound, have been reported by one or more of the earlier workers $[5,7,8,9,14,15]$. In place of comparing the previous data for each material, it is useful to consider reported results on colemanite which has been studied by all these investigators. The frequency range considered is from 650 to $1350 \mathrm{~cm}^{-1}$ since this was the range used by Takeuchi [5]. In general appearance, of all five spectra for colemanite are very similar, but the similarity holds only for the gross features. Between 650 and $1350 \mathrm{~cm}^{-1}$ Takeuchi [5] and Moenke [7] report twelve absorption bands; Plyusnina and Kharitonov [15], fourteen; Akhamanova [14], nine; and the present work, thirteen. Thus the most probable number of bands would seem to be between twelve and fourteen. However, the totals are obtained quite differently by the several workers. Consider, for example, the $1042 \mathrm{~cm}^{-1}$ band of figure 2 which appears to be distinct and well separated from neighboring bands. Akhamanova [14] reports a band at $1050 \mathrm{~cm}^{-1}$, Plyusnina and Kharitonov [15] a strong band at $1048 \mathrm{~cm}^{-1}$ plus two additional bands at 1002 and $1062 \mathrm{~cm}^{-1}$, Moenke [7] a strong band at $1046 \mathrm{~cm}^{-1}$ and Takeuchi's [5] spectra indicate a band at about $1030 \mathrm{~cm}^{-1}$. In addition to these uncertainties in band numbers and locations there are considerable differences in relative intensities and band contours for many of the bands throughout the spectrum. The same considerations apply to comparisons between the present and previous data on the other members of the 2:3:x borates. Possible explanations and implications of these facts will be discussed later.

\subsection{The $\mathrm{MeO} \cdot 3 \mathrm{~B}_{2} \mathrm{O}_{3} \cdot \mathrm{XH}_{2} \mathrm{O}$ Compounds}

Compounds studied with the empirical formula $\mathrm{MeO} \cdot 3 \mathrm{~B}_{2} \mathrm{O}_{3} \cdot \mathrm{XH}_{2} \mathrm{O}$ are tunellite, nobleite, gowerite, synthetic aksaite, veatchite, synthetic calciumveatchite [32], synthetic macallisterite [33], and a synthetic $1: 3: 4$ ? strontium borate. Of these materials, the structure is known only for nobleite and tunellite [34] which are isomorphous. The anion consists of three six-membered rings forming a $\left[\mathrm{B}_{6} \mathrm{O}_{9}(\mathrm{OH})_{2}\right]^{-2}$ unit. The six-membered rings are the same as those found in the $2 \mathrm{MeO} \cdot 3 \mathrm{~B}_{2} \mathrm{O}_{3} \cdot X \mathrm{H}_{2} \mathrm{O}$ compounds and each contains two tetrahedral and one triangular boron. The $\left[\mathrm{B}_{6} \mathrm{O}_{9}(\mathrm{OH})_{2}\right]^{-2}$ ion contains three triangular and three tetrahedral boron groups and is unique in that one oxygen atom is common to all three rings. The ions are linked in sheets through certain of the offring oxygen atoms. The structures of the anions in the other members of this series are not yet known, but it might be expected to be similar, probably linked with differing degrees of hydration and/or polymerization [16].

Data obtained on these materials are given in table 4 and typical spectra are shown in figure 3 . It would be expected that these spectra should show some similarities with those of figure 2 , since the anions are built of similar units and indeed there are many similarities in band positions in the two sets of spectra. However, it was surmised that the coupling between rings in tunellite would be strong enough to produce considerable broadening and band overlap. The reverse situation actually occurs, many bands being clearly resolved and relatively sharp. From the similarities of the spectra (see data of table 4), it is clear that nobleite, tunellite, and the synthetic 1:3:4? synthetic strontium borate have similar anions. Examination of figure 3, shows that it is probable that gowerite has the same anion on the basis of the similarity of the spectra. In gowerite the bands are sharper and appear to be resolved better, a result to be expected if depolymerization of the anion occurs with increased water content. It also appears that veatchite possesses the same anion as tunellite with band broadening and loss of resolution accompanying 


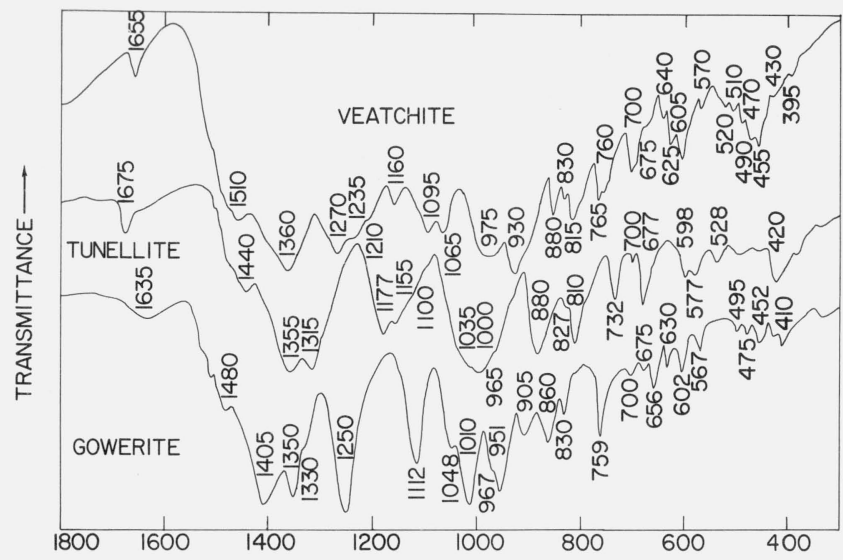

FigURE 3. Infrared absorption spectra of $\mathrm{MeO} \cdot 3 \mathrm{~B}_{2} \mathrm{O}_{3} \cdot \mathrm{XH}_{2} \mathrm{O}$ compounds.

the dehydration and polymerization. From the tabular data (table 4), it is clear that the spectra of veatchite and synthetic calcium-veatchite are very similar and the materials probably contain the same anion. The conclusions with respect to the two magnesium compounds, synthetic aksaite, and synthetic macallisterite, are made with much less certainty; but again it seems probable that these materials also may contain the same anion with differing degrees of hydration and polymeriztion. On the basis of the infrared spectra alone, therefore, it is concluded that all the $\mathrm{MeO} \cdot 3 \mathrm{~B}_{2} \mathrm{O}_{3} \cdot \mathrm{XH}_{2} \mathrm{O}$ compounds probably contain similar anions. These spectra do not appear to have been reported previously.

TABLE 4. Infrared absorption spectra of $\mathrm{MeO} \cdot 3 \mathrm{~B}_{2} \mathrm{O}_{3} \cdot \mathrm{XH}_{2} \mathrm{O}$ compounds

\begin{tabular}{|c|c|c|}
\hline Nobleite & Tunellite & $\begin{array}{c}\text { Synthetic } \\
\mathrm{SrO} \cdot 3 \mathrm{~B}_{2} \mathrm{O}_{3} \cdot 4 \mathrm{H}_{2} \mathrm{O} \text { ? }\end{array}$ \\
\hline $\begin{array}{l}3540 \mathrm{mb} \\
3380 \mathrm{svb} \\
3200 \mathrm{svb} \\
2400 \mathrm{svb} \\
1675 \mathrm{mvb} \\
1385 \mathrm{sbsh} \\
1322 \mathrm{sb} \\
1300 \mathrm{msh} \\
1180 \mathrm{mb} \\
1160 \mathrm{mb} \\
1125 \mathrm{mb} \\
1107 \mathrm{~m} \\
1033 \mathrm{msh} \\
965 \mathrm{sb} \\
930 \mathrm{msh} \\
880 \mathrm{sb} \\
827 \mathrm{~m} \\
805 \mathrm{sb} \\
737 \mathrm{~m} \\
705 \mathrm{~m} \\
670 \mathrm{mb} \\
602 \mathrm{~m} \\
570 \mathrm{w} \\
460 \mathrm{wb} \\
425 \mathrm{w}\end{array}$ & $\begin{array}{l}1675 \mathrm{mb} \\
1440 \mathrm{msh} \\
1355 \mathrm{sb} \\
1315 \mathrm{sb} \\
1177 \mathrm{mb} \\
1155 \mathrm{mb} \\
1100 \mathrm{w} \\
1035 \mathrm{msh} \\
1000 \mathrm{sb} \\
965 \mathrm{msh} \\
880 \mathrm{sb} \\
827 \mathrm{msh} \\
810 \mathrm{~s} \\
732 \mathrm{~m} \\
700 \mathrm{w} \\
677 \mathrm{~m} \\
598 \mathrm{~m} \\
577 \mathrm{~m} \\
528 \mathrm{w} \\
420 \mathrm{~m}\end{array}$ & $\begin{array}{c}1460 \mathrm{mb} \\
1375 \mathrm{svb} \\
1325 \mathrm{svb} \\
1180 \mathrm{sb} \\
1125 \mathrm{sb} \\
1100 \mathrm{w} \\
1010 \mathrm{sb} \\
962 \mathrm{svb} \\
927 \mathrm{mb} \\
875 \mathrm{sb} \\
810 \mathrm{sb} \\
735 \mathrm{~m} \\
670 \mathrm{mb}\end{array}$ \\
\hline
\end{tabular}

TABLE 4. Infrared absorption spectra of $\mathrm{MeO} \cdot 3 \mathrm{~B}_{2} \mathrm{O}_{3} \cdot \mathrm{XH}_{2} \mathrm{O}$ compounds-Continued

\begin{tabular}{l|l}
\hline Veatchite & Synthetic Ca-Veatchite \\
\hline $3420-2900 \mathrm{~b}$ & \\
$1655 \mathrm{w}$ & $1665 \mathrm{w}$ \\
$1510 \mathrm{ssh}$ & \\
$1360 \mathrm{sb}$ & $1390 \mathrm{sb}$ \\
$1270 \mathrm{sb}$ & $1265 \mathrm{wsh}$ \\
$1235 \mathrm{msh}$ & $1240 \mathrm{sb}$ \\
$1210 \mathrm{wsh}$ & $1180 \mathrm{msh}$ \\
$1160 \mathrm{~m}$ & $1130 \mathrm{~m}$ \\
$1095 \mathrm{mb}$ & $1075 \mathrm{mb}$ \\
$1065 \mathrm{mb}$ & $975 \mathrm{sb}$ \\
$975 \mathrm{sb}$ & $910 \mathrm{sb}$ \\
$930 \mathrm{sb}$ & $870 \mathrm{~m}$ \\
$880 \mathrm{~m}$ & $832 \mathrm{~m}$ \\
$830 \mathrm{w}$ & $810 \mathrm{~m}$ \\
$815 \mathrm{~m}$ & $755 \mathrm{~m}$ \\
$765 \mathrm{~m}$ & $745 \mathrm{wsh}$ \\
$760 \mathrm{~m}$ & $700 \mathrm{w}$ \\
$700 \mathrm{~m}$ & \\
$675 \mathrm{msh}$ & $650 \mathrm{w}$ \\
$640 \mathrm{w}$ & $610 \mathrm{~m}$ \\
$625 \mathrm{~m}$ & $600 \mathrm{wsh}$ \\
$605 \mathrm{~m}$ & $572 \mathrm{wsh}$ \\
$570 \mathrm{w}$ & $535 \mathrm{wb}$ \\
$520 \mathrm{w}$ & \\
$510 \mathrm{w}$ & $495 \mathrm{w}$ \\
$490 \mathrm{w}$ & \\
$470 \mathrm{~m}$ & \\
$455 \mathrm{~m}$ & \\
$430 \mathrm{msh}$ & \\
$395 \mathrm{mb}$ & \\
\hline & \\
\hline
\end{tabular}

TABLE 4. Infrared absorption spectra of $\mathrm{MeO} \cdot 3 \mathrm{~B}_{2} \mathrm{O}_{3} \cdot \mathrm{XH}_{2} \mathrm{O}$ compounds-Continued

\begin{tabular}{|c|c|c|}
\hline Gowerite & Synthetic Aksaite & $\begin{array}{c}\text { Synthetic } \\
\text { MacAllisterite }\end{array}$ \\
\hline $\begin{array}{l}1635 \mathrm{wb} \\
1480 \mathrm{msh} \\
1405 \mathrm{~s} \\
1350 \mathrm{~s} \\
1330 \mathrm{msh} \\
1250 \mathrm{~s} \\
1112 \mathrm{~s} \\
1048 \mathrm{ssh} \\
1010 \mathrm{~s} \\
967 \mathrm{msh} \\
951 \mathrm{~s} \\
905 \mathrm{mb} \\
860 \mathrm{mb} \\
830 \mathrm{~m} \\
759 \mathrm{~m} \\
700 \mathrm{w} \\
675 \mathrm{w} \\
656 \mathrm{~m} \\
630 \mathrm{w} \\
602 \mathrm{w} \\
567 \mathrm{w} \\
495 \mathrm{w} \\
475 \mathrm{w} \\
452 \mathrm{w} \\
410 \mathrm{w}\end{array}$ & $\begin{array}{l}3600 \mathrm{~s} \\
3450-2400 \mathrm{sb} \\
1652 \mathrm{mb} \\
1485 \mathrm{msh} \\
1425 \mathrm{sb} \\
1385 \mathrm{sb} \\
1325 \mathrm{sb} \\
1245 \mathrm{sb} \\
1210 \mathrm{sb} \\
1155 \mathrm{mb} \\
1095 \mathrm{sb} \\
1020 \mathrm{sb} \\
\\
950 \mathrm{sb} \\
898 \mathrm{mb} \\
850 \mathrm{mb} \\
800 \mathrm{sb} \\
725 \mathrm{w} \\
575 \mathrm{mb} \\
655 \mathrm{w} \\
\\
525 \mathrm{w} \\
455 \mathrm{w} \\
410 \mathrm{w}\end{array}$ & $\begin{array}{l}1470 \mathrm{msh} \\
1410 \mathrm{sb} \\
1358 \mathrm{sb} \\
1240 \mathrm{~s} \\
1158 \mathrm{mb} \\
1122 \mathrm{sb} \\
1060 \mathrm{sb} \\
1005 \mathrm{msh} \\
980 \mathrm{~m} \\
965 \mathrm{~m} \\
880 \mathrm{msh} \\
855 \mathrm{~s} \\
812 \mathrm{~s} \\
698 \mathrm{wb} \\
670 \mathrm{~m}\end{array}$ \\
\hline
\end{tabular}

\subsection{The $2 \mathrm{MeO} \cdot 7 \mathrm{~B}_{2} \mathrm{O}_{3} \cdot 8 \mathrm{H}_{2} \mathrm{O}$ Compounds}

Three members of this series were studied, the data are given in table 5 and spectra are shown in figure 4. The marked similarity of the spectra and the compounds makes it almost certain that the anions are identical. The structures of the anions are not known and the spectra are too complex to attempt to predict the anion on this basis alone. There is no doubt that the anion contains both three-fold and fourfold coordinated boron as shown by the strong bands 


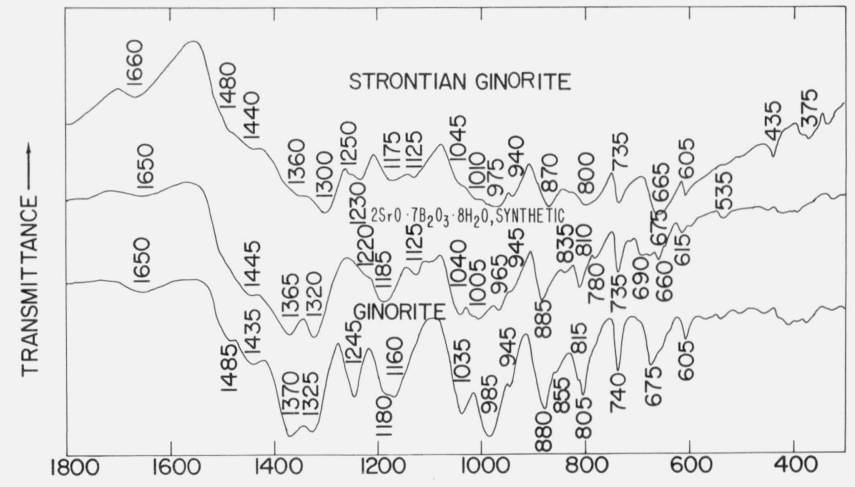

Figure 4. Infrared absorption spectra of $2 \mathrm{MeO} \cdot 7 \mathrm{~B}_{2} \mathrm{O}_{3} \cdot 8 \mathrm{H}_{2} \mathrm{O}$ compounds.

TABLE 5. Infrared absorption spectra of $2 \mathrm{MeO} \cdot 7 \mathrm{~B}_{2} \mathrm{O}_{3} \cdot 8 \mathrm{H}_{2} \mathrm{O}$ compounds

\begin{tabular}{l|l|l}
\hline \hline Ginorite & Strontian Ginorute & $\begin{array}{c}2 \mathrm{SrO} \cdot 7 \mathrm{~B}_{2} \mathrm{O}_{3} \cdot 8 \mathrm{H}_{2} \mathrm{O} \\
\text { Synthetic }\end{array}$ \\
\hline $3250 \mathrm{vsvb}$ & & \\
$1650 \mathrm{wvb}$ & $1660 \mathrm{mvb}$ & $1650 \mathrm{wvb}$ \\
$1485 \mathrm{msh}$ & $1480 \mathrm{mbsh}$ & $1445 \mathrm{mbsh}$ \\
$1435 \mathrm{msh}$ & $1440 \mathrm{mbsh}$ & $1365 \mathrm{~s}$ \\
$1370 \mathrm{~s}$ & $1360 \mathrm{svb}$ & $1320 \mathrm{~s}$ \\
$1325 \mathrm{~s}$ & $1300 \mathrm{sb}$ & $1220 \mathrm{mb}$ \\
$1245 \mathrm{~s}$ & $1250 \mathrm{~m}$ & $1185 \mathrm{~s}$ \\
& $1230 \mathrm{mb}$ & $1125 \mathrm{~m}$ \\
$1180 \mathrm{~s}$ & $1175 \mathrm{svb}$ & $1040 \mathrm{~s}$ \\
$1160 \mathrm{~s}$ & $1125 \mathrm{mvb}$ & $1005 \mathrm{sb}$ \\
$1035 \mathrm{~m}$ & $1045 \mathrm{~m}$ & $965 \mathrm{~m}$ \\
$985 \mathrm{sb}$ & $1010 \mathrm{sb}$ & $945 \mathrm{msh}$ \\
$945 \mathrm{~m}$ & $975 \mathrm{svb}$ & $885 \mathrm{~s}$ \\
$880 \mathrm{~s}$ & $940 \mathrm{sb}$ & $835 \mathrm{~m}$ \\
$855 \mathrm{msh}$ & $870 \mathrm{~s}$ & $810 \mathrm{~s}$ \\
$815 \mathrm{msh}$ & & $780 \mathrm{msh}$ \\
$805 \mathrm{~s}$ & $800 \mathrm{sb}$ & $735 \mathrm{~s}$ \\
$740 \mathrm{~s}$ & $735 \mathrm{~s}$ & $690 \mathrm{~m}$ \\
$675 \mathrm{sb}$ & $655 \mathrm{sb}$ & $675 \mathrm{~m}$ \\
$605 \mathrm{~m}$ & $605 \mathrm{~m}$ & $660 \mathrm{~m}$ \\
& & $615 \mathrm{w}$ \\
& $435 \mathrm{~m}$ & $535 \mathrm{w}$ \\
\hline
\end{tabular}

near 1400 and $1000 \mathrm{~cm}^{-1}$ respectively. In addition the spectra show a strong resemblance to the previous spectra for compounds containing six-membered rings of alternate boron and oxygen atoms, with one triangular and two tetrahedral boron atoms. Consequently, it appears likely that these rings may exist in the anions. The relative weakness of lower frequency vibrations (i.e., below $600 \mathrm{~cm}^{-1}$ ) in these spectra, however, is an indication that the anions are not coupled six-membered rings and it is very unlikely that the anions are so small that no low frequency vibrations exist. It is probable that the symmetry of the anions is sufficiently high that lower frequency modes are much weaker than in the previous compounds. Again there do not appear to be any previous reports of spectra of these materials.

\subsection{Miscellaneous Divalent Metal Borates}

Data on the $4 \mathrm{CaO} \cdot 5 \mathrm{~B}_{2} \mathrm{O}_{3} \cdot X \mathrm{H}_{2} \mathrm{O}$ compounds are given in table 6 together with those for preobrazhens-

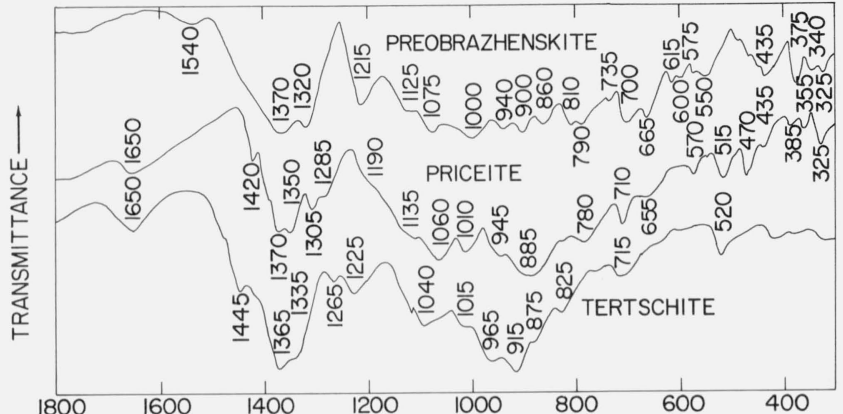

FIGURE 5. Infrared absorption spectra of miscellaneous hydrated divalent metal borates.

TABLE 6. Infrared absorption spectra of miscellaneous divalent metal borate compounds

\begin{tabular}{l|l|l}
\hline & & \\
Priceite & Tertschite & Preobrazhenskite \\
\hline & & \\
$1650 \mathrm{mvb}$ & $1650 \mathrm{mb}$ & $1540 \mathrm{mvb}$ \\
$1420 \mathrm{~m}$ & $1445 \mathrm{~m}$ & $1370 \mathrm{sb}$ \\
$1370 \mathrm{~s}$ & $1365 \mathrm{~s}$ & $1320 \mathrm{~s}$ \\
$1350 \mathrm{~s}$ & $1335 \mathrm{ssh}$ & \\
$1305 \mathrm{~s}$ & & \\
$1285 \mathrm{msh}$ & $1265 \mathrm{w}$ & $1215 \mathrm{sb}$ \\
$1190 \mathrm{msh}$ & $1225 \mathrm{~m}$ & $1125 \mathrm{msh}$ \\
$1135 \mathrm{msh}$ & $1040 \mathrm{sb}$ & $1075 \mathrm{sb}$ \\
$1060 \mathrm{sb}$ & $1015 \mathrm{msh}$ & $940 \mathrm{svb}$ \\
$1010 \mathrm{sb}$ & $965 \mathrm{sb}$ & $900 \mathrm{~m}$ \\
$945 \mathrm{ssh}$ & $915 \mathrm{sb}$ & \\
$885 \mathrm{svb}$ & $875 \mathrm{msh}$ & $860 \mathrm{mvb}$ \\
$780 \mathrm{sb}$ & $825 \mathrm{~m}$ & $810 \mathrm{~m}$ \\
$710 \mathrm{~m}$ & $715 \mathrm{~m}$ & $790 \mathrm{~m}$ \\
$655 \mathrm{mb}$ & & $735 \mathrm{w}$ \\
& & $700 \mathrm{sb}$ \\
$570 \mathrm{~m}$ & $565 \mathrm{mb}$ \\
$515 \mathrm{~m}$ & $520 \mathrm{~m}$ & $615 \mathrm{~m}$ \\
$470 \mathrm{~m}$ & & $600 \mathrm{w}$ \\
& & $575 \mathrm{w}$ \\
$435 \mathrm{w}$ & & $550 \mathrm{mb}$ \\
$385 \mathrm{~m}$ & & $435 \mathrm{mvb}$ \\
$355 \mathrm{w}$ & & $375 \mathrm{~m}$ \\
$325 \mathrm{~m}$ & & $340 \mathrm{~m}$ \\
& & $325 \mathrm{~m}$ \\
\hline & &
\end{tabular}

kite $-3 \mathrm{MgO} \cdot 5 \mathrm{~B}_{2} \mathrm{O}_{3} \cdot 4 \frac{1}{2} \mathrm{H}_{2}\left(\mathrm{O}_{\mathrm{L}}\right.$ ?] [35]. The spectra are shown in figure 5 . The three materials show evidence of both triangular and tetrahedral boron in the strong bands in the $1300-1400 \mathrm{~cm}^{-1}$ and $800-1000 \mathrm{~cm}^{-1}$ region respectively. The spectra of priceite and tertschite are very similar and these materials may contain similar anions. The spectrum of preobrazhenskite is indicative of a large anion with considerable interaction between the anion structural units.

From the data obtained here the spectra of pandermite and priceite are considered to be identical. The sample of priceite yielded much the better spectrum of the two specimens, that for pandermite being less well resolved. However, for each band found in the spectrum of pandermite a corresponding band is observed in the priceite with frequencies differing at most by $\pm 1 \mathrm{~cm}^{-1}$. In addition, the same relative intensity relationships are shown by the bands in the two materials. It seems possible to conclude that these materials are most probably identical [36]. 
The spectrum of priceite (pandermite) has been reported by other workers $[5,7,14,15]$ and that of tertschite by Meixner and Moenke [12]. Comparison of the present and previous results leads to the same conclusions mentioned earlier. The spectra for a given material are in superficial agreement. There are many discrepancies when details are examined.

Data obtained on other divalent metal borates are given in table 7 with spectra for ulexite and kaliborite shown in figure 6 . The anions of probertite and ulexite are known to be a ring structure containing three tetrahedra and two triangles with one tetrahedron being common to both rings $[37,38]$. From the tabulated data it is clear that the infrared spectra corroborate the similarity of the anions in these materials probertite and ulexite. The spectrum of kaliborite is very poorly resolved in the $\nu_{3}$ region for tetrahedral borate groups, but is otherwise similar to the spectra of ulexite. The parahilgardite yielded a very poor spectrum and it is suspected that this material was contaminated with $\mathrm{CaCO}_{3}$ as the 875 and $725 \mathrm{~cm}^{-1}$ bands strongly resemble the $\nu_{2}$ and $\nu_{4}$ bands of calcite.

TABLE 7. Infrared absorption spectra of miscellaneous borate compounds

\begin{tabular}{|c|c|c|c|}
\hline Ulexite & Probertite & Kaliborite & Parahilgardite \\
\hline $\begin{array}{l}3562 \mathrm{~s} \\
3400 \mathrm{sb} \\
3000 \mathrm{vsvb} \\
1650 \mathrm{mb} \\
1620 \mathrm{mb} \\
1470 \mathrm{~m} \\
1415 \mathrm{sb} \\
1390 \mathrm{~s} \\
1355 \mathrm{~s} \\
1315 \mathrm{~s} \\
1205 \mathrm{~s} \\
1090 \mathrm{ssh} \\
1050 \mathrm{sb} \\
995 \mathrm{~s} \\
975 \mathrm{~s} \\
950 \mathrm{ssh} \\
925 \mathrm{msh} \\
855 \mathrm{~s} \\
825 \mathrm{ssh} \\
740 \mathrm{~m} \\
710 \mathrm{~m} \\
640 \mathrm{~m} \\
530 \mathrm{~m} \\
\\
430 \mathrm{mb} \\
350 \mathrm{~m}\end{array}$ & $\begin{array}{l}3620 \mathrm{~s} \\
3550 \mathrm{~s} \\
3350 \mathrm{vsvb} \\
1650 \mathrm{mvb} \\
1470 \mathrm{~m} \\
1425 \mathrm{msh} \\
1375 \mathrm{~s} \\
1325 \mathrm{sb} \\
1210 \mathrm{~m} \\
1130 \mathrm{ssh} \\
1080 \mathrm{sb} \\
1040 \mathrm{~m} \\
985 \mathrm{msh} \\
955 \mathrm{~s} \\
930 \mathrm{~s} \\
900 \mathrm{~s} \\
830 \mathrm{~s} \\
750 \mathrm{~m} \\
675 \mathrm{~m} \\
555 \mathrm{w} \\
515 \mathrm{~m} \\
440 \mathrm{~m} \\
380 \mathrm{~m}\end{array}$ & $\begin{array}{l}1410 \mathrm{msh} \\
1350 \mathrm{sb} \\
1185 \mathrm{svb} \\
1080 \mathrm{sb} \\
1000-750 \mathrm{svb}\end{array}$ & $\begin{array}{l}875 \mathrm{~s}\left(\mathrm{CcCO}_{3} ?\right) \\
790 \mathrm{~s} \\
775 \\
725 \mathrm{~s}\left(\mathrm{CaCO}_{3} ?\right)\end{array}$ \\
\hline
\end{tabular}

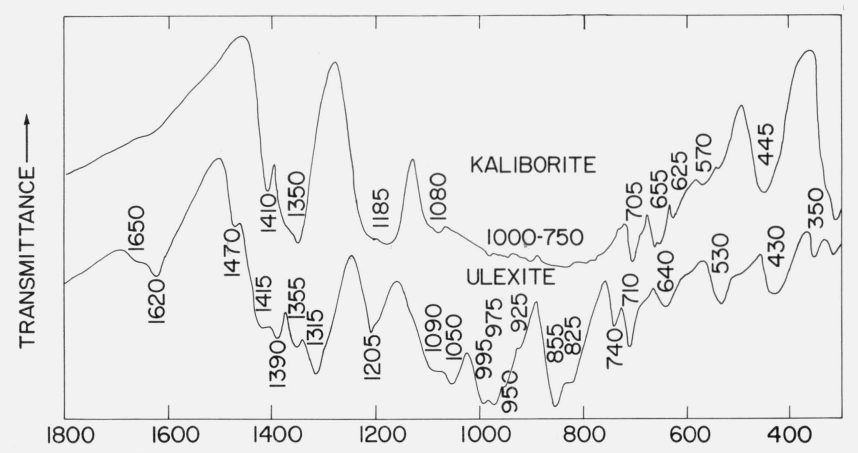

FIGURE 6. Infrared absorption spectra of hydrated borates containing both mono- and divalent metal ions.

\section{Monovalent Metal Borates}

\subsection{The $\mathrm{Me}_{2} \mathrm{O} \cdot 2 \mathrm{~B}_{2} \mathrm{O}_{3} \cdot \mathrm{XH}_{2} \mathrm{O}$ Compounds}

Several borates of the type $\mathrm{Me}_{2} \mathrm{O} \cdot 2 \mathrm{~B}_{2} \mathrm{O}_{3} \cdot X \mathrm{H}_{2} \mathrm{O}$ were studied and the data are tabulated in table 8 . Typical spectra for tincalconite and potassium tetraborate tetrahydrate are shown in figure 7 . Morimoto [39] has determined the structure of borax and found that the anion consists of isolated $\left[\mathrm{B}_{4} \mathrm{O}_{5}(\mathrm{OH})_{4}\right]^{-2}$ rings. Marezio et al., [40] have found the same anion in potassium tetraborate tetrahydrate. The rings contain two triangular and two tetrahedral borate groups joined at common oxygen atoms. The two tetrahedral groups are further linked by means of an oxygen bridge across the ring. All off-ring oxygen atoms are hydrated in borax.

As noted in the previous study the alkali borates yield very poorly resolved spectra under the conditions used here. From the tabulated absorption bands it is noted that all the materials show similar spectra and probably all contain the basic $\left[\mathrm{B}_{4} \mathrm{O}_{5}(\mathrm{OH})_{4}\right]^{-2}$ anion

TABLE 8. Infrared absorption spectra of $\mathrm{Me}_{2} \mathrm{O} \cdot 2 \mathrm{~B}_{2} \mathrm{O}_{3} \cdot \mathrm{XH}_{2} \mathrm{O}$ compounds

\begin{tabular}{|c|c|c|c|}
\hline Kernite & Tincalconite & Borax & $\underset{\text { synthetic }}{\mathrm{K}_{2} \mathrm{O} \cdot 2 \mathrm{~B}_{2} \mathrm{O}_{3} \cdot 4 \mathrm{H}_{2} \mathrm{O}}$ \\
\hline $\begin{array}{l}1700 \mathrm{mvb} \\
1460 \mathrm{~m} \\
1425 \mathrm{msh} \\
1340 \mathrm{vsvb} \\
1160 \mathrm{~m} \\
1075 \mathrm{mb} \\
1010 \mathrm{svb} \\
950 \mathrm{vsvb} \\
865 \mathrm{svb} \\
820 \mathrm{svb}\end{array}$ & $\begin{array}{l}3500 \mathrm{sb} \\
3340 \mathrm{vsb} \\
3000 \mathrm{svb} \\
2400 \mathrm{svb} \\
1630 \mathrm{mvb} \\
1455 \mathrm{msh} \\
1405 \mathrm{svb} \\
1340 \mathrm{vsvb} \\
1190 \mathrm{msh} \\
1155 \mathrm{sb} \\
1125 \mathrm{svb} \\
1075 \mathrm{svb} \\
1025 \mathrm{svb} \\
985 \mathrm{sb} \\
940 \mathrm{sb} \\
805 \mathrm{sb} \\
750 \mathrm{mvb} \\
665 \mathrm{mvb} \\
600 \mathrm{mvb} \\
520 \mathrm{mvb} \\
425 \mathrm{mvb}\end{array}$ & $\begin{array}{l}3500- \\
3000 \mathrm{vsvb} \\
2000 \mathrm{svb} \\
1620 \mathrm{mvb} \\
1450 \mathrm{msh} \\
1390 \mathrm{svb} \\
1330 \mathrm{vsvb} \\
1275 \mathrm{mvb} \\
1155 \mathrm{mb} \\
1123 \mathrm{mvb} \\
1070 \mathrm{mb} \\
980 \mathrm{sb} \\
935 \mathrm{sb} \\
800 \mathrm{svb} \\
750 \mathrm{svb} \\
\\
665 \mathrm{mvb} \\
\\
595 \mathrm{wb} \\
505 \mathrm{mshvb} \\
420 \mathrm{sb} \\
395 \mathrm{~s}\end{array}$ & $\begin{array}{l}1625 \mathrm{mvb} \\
1395 \mathrm{svb} \\
1320 \mathrm{vsvb} \\
1220 \mathrm{~s} \\
1160 \mathrm{~m} \\
1080 \mathrm{sb} \\
1060 \mathrm{msh} \\
970 \mathrm{sb} \\
905 \mathrm{sb} \\
805 \mathrm{svb} \\
745 \mathrm{w} \\
710 \mathrm{~m} \\
665 \mathrm{mb} \\
600 \\
560 \mathrm{mvb} \\
490 \mathrm{~m} \\
450 \mathrm{mb} \\
422 \mathrm{mvb} \\
390 \mathrm{~m}\end{array}$ \\
\hline
\end{tabular}

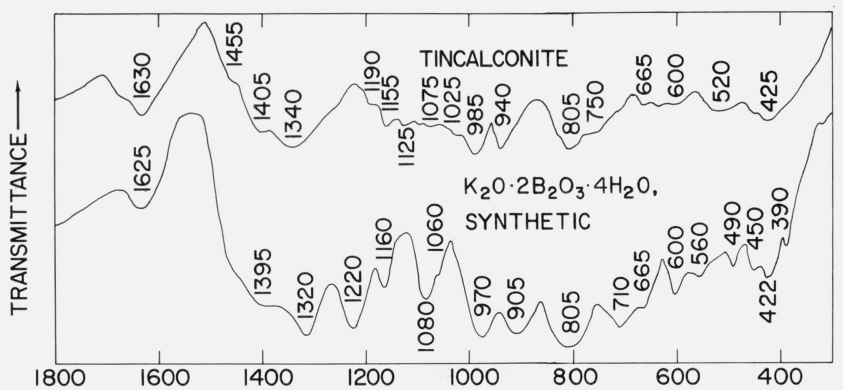

FIGURE 7. Infrared absorption spectra of $\mathrm{Me}_{2} \mathrm{O} \cdot 2 \mathrm{~B}_{2} \mathrm{O}_{3} \cdot \mathrm{XH}_{2} \mathrm{O}$ compounds. 
in some state of hydration or polymerization. The specimen of $\mathrm{K}_{2} \mathrm{~B}_{4} \mathrm{O}_{7} \cdot 4 \mathrm{H}_{2} \mathrm{O}$ used was obtained from a commercially available reagent labeled $\mathrm{K}_{2} \mathrm{~B}_{4} \mathrm{O}_{7} \cdot 5 \mathrm{H}_{2} \mathrm{O}$. The $\mathrm{x}$-ray diffraction pattern of this compound can be indexed readily from the unit cell data of Marezio et al., [40] and it has been tabulated as the tetrahydrate.

The previous data obtained on this group of materials together with the present data exhibit a confusing pattern. The spectra for borax of Miller and Wilkins [4] and of Moenke [7] agree with each other but differ considerably from that of Akhamanova [14] and the present results. Miller and Wilkins [4] reported the spectrum of $\mathrm{K}_{2} \mathrm{~B}_{4} \mathrm{O}_{7} \cdot 5 \mathrm{H}_{2} \mathrm{O}$ which closely resembles their spectrum of borax but differs considerably from the spectrum of $\mathrm{K}_{2} \mathrm{~B}_{4} \mathrm{O}_{7} \cdot 4 \mathrm{H}_{2} \mathrm{O}$ obtained here. Takeuchi's [5] results for kernite agree well with the present data but both disagree in many respects with the results of Moenke [7]. The overall lack of agreement between the spectra obtained by different workers appears to be greatest for these materials. This question will be discussed later.

\subsection{The $\mathrm{Me}_{2} \mathrm{O} \cdot 5 \mathrm{~B}_{2} \mathrm{O}_{3} \cdot \mathrm{XH}_{2} \mathrm{O}$ Compounds}

Data for the minerals ammonium larderellite and ammonioborite [41] and the synthetic 1:5:10 sodium borate are given in table 9. Representative spectra are not shown because there is strong absorption and poor resolution throughout the entire spectral range. The strong absorption is to be expected in the two ammonium compounds because they contain the infrared active $\mathrm{NH}_{4}^{+}$ion in addition to water of hydration and a complex borate anion. Christ [16] has predicted that sborgite, larderellite, and ammonioborite have the same anion and the data of table 9 confirm this prediction for the ammonium compounds with little question. The spectrum of the 1:5:10 synthetic sodium borate differs from those of the ammonium borates in many details but not in gross features. Because of the unknown effect of the $\mathrm{NH}_{4}^{+}$ion on the spectra, it is possible that all three compounds contains similar anions.

TABLE 9. Infrared absorption spectra of $\mathrm{Me}_{2} \mathrm{O} \cdot 5 \mathrm{~B}_{2} \mathrm{O}_{3} \cdot \mathrm{XH}_{2} \mathrm{O}$ compounds

\begin{tabular}{l|l|l}
\hline $\begin{array}{l}\mathrm{Na}_{2} \mathrm{O} \cdot 5 \mathrm{~B}_{2} \mathrm{O}_{3}: 10 \mathrm{H}_{2} \mathrm{O} \\
\text { synthetic }\end{array}$ & Ammonioborite & Larderellite \\
& & \\
$1670 \mathrm{mb}$ & & \\
& $1650 \mathrm{mvb}$ & \\
$1375 \mathrm{vsvb}$ & $1425 \mathrm{vsvb}$ & $1425 \mathrm{vsvb}$ \\
$1300 \mathrm{vsvb}$ & $1235 \mathrm{vsvb}^{\mathrm{vsvb}}$ & $1350 \mathrm{vsvb}$ \\
$1195 \mathrm{~m}$ & $1190 \mathrm{sb}$ & $1225 \mathrm{mvb}$ \\
$1145 \mathrm{svb}$ & $1160 \mathrm{mb}$ & $1185 \mathrm{~s}$ \\
$1075 \mathrm{sb}$ & $1085 \mathrm{sb}$ & $1165 \mathrm{~m}$ \\
$1045 \mathrm{~m}$ & $1055 \mathrm{sb}$ & $1085 \mathrm{mvb}$ \\
$1010 \mathrm{sb}$ & $1015 \mathrm{svb}$ & $1055 \mathrm{mb}$ \\
$950 \mathrm{~m}$ & $940 \mathrm{svb}$ & $940 \mathrm{mb}$ \\
$925 \mathrm{~s}$ & $915 \mathrm{sb}$ & $920 \mathrm{mvb}$ \\
$910 \mathrm{~s}$ & $880 \mathrm{w}$ & $880 \mathrm{w}$ \\
$780 \mathrm{~s}$ & $820 \mathrm{mvb}$ & $810 \mathrm{mb}$ \\
$765 \mathrm{~s}$ & $775 \mathrm{sb}$ & $775 \mathrm{~s}$ \\
$675 \mathrm{vsvb}$ & $740 \mathrm{~m}$ & \\
$470 \mathrm{mb}$ & $675 \mathrm{sb}$ & $675 \mathrm{mvb}$ \\
$440 \mathrm{mb}$ & $545 \mathrm{~s}$ & $545 \mathrm{~s}$ \\
$375 \mathrm{mvb}$ & $510 \mathrm{mb}$ & $455 \mathrm{~m}$ \\
& $460 \mathrm{mb}$ & $425 \mathrm{mvb}$ \\
\hline
\end{tabular}

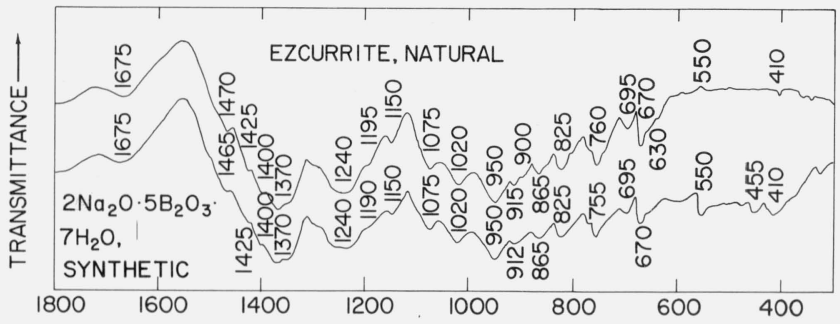

FIGURE 8. Infrared absorption spectra of $2 \mathrm{Na}_{2} \mathrm{O} \cdot 5 \mathrm{~B}_{2} \mathrm{O}_{3} \cdot 7 \mathrm{H}_{2} \mathrm{O}$ compounds.

\subsection{The $2 \mathrm{Me}_{2} \mathrm{O} \cdot 5 \mathrm{~B}_{2} \mathrm{O}_{3} \cdot \mathrm{XH}_{2} \mathrm{O}$ Compounds}

Ezcurrite and the $2: 5: X$ synthetic sodium borates show rather poor spectra characterized by strong absorption throughout the spectral range studied. The absorption bands observed are listed in table 10 and figure 8 shows the spectra for a synthetic and a natural ezcurrite. It is obvious from figure 8 that despite the rather poor resolution that these materials are almost certainly the same insofar as the anions are concerned. In addition, the fact that, band for band the frequencies are the same within experimental error may be interpreted to mean that the materials are chemically and structurally identical. This conclusion is based on previous studies which showed that change of anion or crystal structure generally produces shifting of some bands in the infrared spectrum [42]. The close similarity in the spectra of all three minerals listed in table 10 indicates that the anions are similar.

TABLE 10. Infrared absorption spectra of $2 \mathrm{Me}_{2} \mathrm{O} \quad 5 \mathrm{~B}_{2} \mathrm{O}_{3} \quad \mathrm{XH}_{2} \mathrm{O}$ compounds

\begin{tabular}{l|c|c}
\hline \hline Ezcurrite & $\begin{array}{c}2 \mathrm{Na}_{2} \mathrm{O} \cdot 5 \mathrm{~B}_{2} \mathrm{O}_{3} \cdot 5 \mathrm{H}_{2} \mathrm{O} \\
\text { Synthetic }\end{array}$ & $\begin{array}{c}2 \mathrm{Na}_{2} \mathrm{O} \cdot 5 \mathrm{~B}_{2} \mathrm{O}_{3} \cdot 4 \mathrm{H}_{2} \mathrm{O} \\
\text { Synthetic }\end{array}$ \\
\hline $1675 \mathrm{mvb}$ & $1625 \mathrm{mvb}$ & $1650 \mathrm{mvb}$ \\
$1470 \mathrm{mb}$ & $1465 \mathrm{mb}$ & $1440 \mathrm{mvb}$ \\
$1425 \mathrm{~m}$ & $1400 \mathrm{mb}$ & $1360 \mathrm{svb}$ \\
$1400 \mathrm{mbsh}$ & $1350 \mathrm{vsvb}$ & $1325 \mathrm{svb}$ \\
$1370 \mathrm{vsb}$ & $1245 \mathrm{svb}$ & $1250 \mathrm{mvb}$ \\
$1240 \mathrm{sb}$ & & $1230 \mathrm{svb}$ \\
$1195 \mathrm{msh}$ & $1045 \mathrm{mvb}$ & $1150 \mathrm{~m}$ \\
$1150 \mathrm{~m}$ & $1015 \mathrm{svb}$ & $1070 \mathrm{sb}$ \\
$1075 \mathrm{mb}$ & $945 \mathrm{svb}$ & $925 \mathrm{sbb}$ \\
$1020 \mathrm{mb}$ & & \\
$950 \mathrm{sb}$ & $870 \mathrm{~m}$ & $880 \mathrm{svb}$ \\
$915 \mathrm{~m}$ & $825 \mathrm{mvb}$ & $830 \mathrm{mvb}$ \\
$900 \mathrm{w}$ & $740 \mathrm{mvb}$ & $740 \mathrm{mvb}$ \\
$865 \mathrm{~m}$ & $695 \mathrm{mb}$ & $695 \mathrm{mvb}$ \\
$825 \mathrm{~m}$ & $670 \mathrm{mvb}$ & $650 \mathrm{mb}$ \\
$760 \mathrm{~m}$ & $630 \mathrm{w}$ & $600 \mathrm{mvb}$ \\
$695 \mathrm{~m}$ & $550 \mathrm{mvb}$ & $550 \mathrm{~m}$ \\
$670 \mathrm{~s}$ & $455 \mathrm{mvb}$ & $440 \mathrm{mb}$ \\
$550 \mathrm{w}$ & $410 \mathrm{mvb}$ & \\
$455 \mathrm{w}$ & & \\
$410 \mathrm{mb}$ & \multicolumn{2}{c}{} \\
\hline
\end{tabular}

\subsection{Miscellaneous Borates}

Data for three borates not readily classified with the previous groups are given in table 11 and the spectra are shown in figure 9. The data for szaibelyite and 


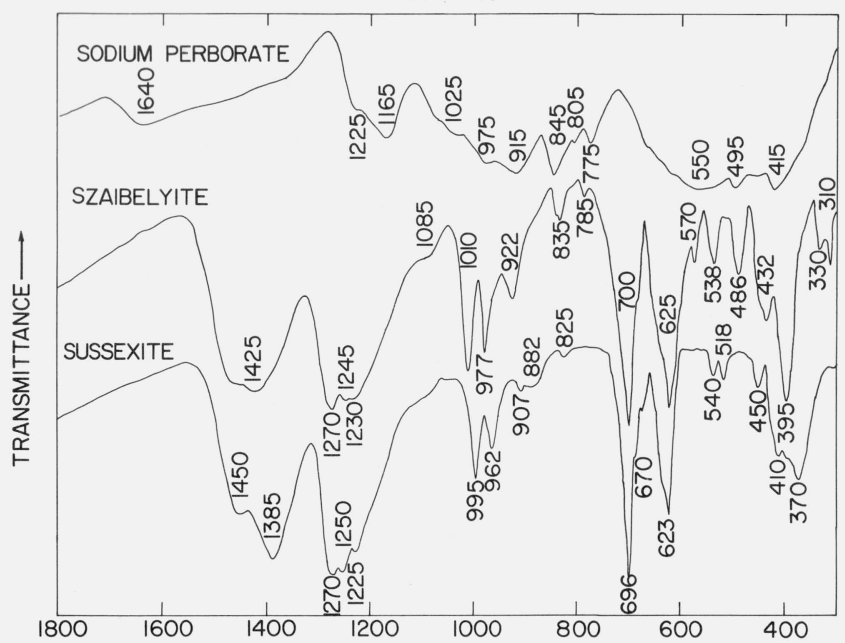

FIGURE 9. Infrared absorption spectra of miscellaneous hydrated borates.

TABLE 11. Infrared absorption spectra of miscellaneous borate compounds

\begin{tabular}{l|l|l}
\hline \hline $\begin{array}{l}\mathrm{NaBO}_{3} \cdot 4 \mathrm{H}_{2} \mathrm{O} \text { sodium } \\
\text { perborate }\end{array}$ & Szaibelyite & Sussexite \\
\hline & & \\
$3590 \mathrm{~s}$ & $3555 \mathrm{~s} \mathrm{sharp}$ & \\
$3500-3000 \mathrm{svb}$ & $1425 \mathrm{vs}$ & $1450 \mathrm{sb}$ \\
$1640 \mathrm{wvb}$ & $1270 \mathrm{~s}$ & $1385 \mathrm{~s}$ \\
$1225 \mathrm{msh}$ & $1245 \mathrm{~s}$ & $1270 \mathrm{~s}$ \\
$1165 \mathrm{mvb}$ & $1230 \mathrm{~s}$ & $1250 \mathrm{~s}$ \\
$1025 \mathrm{mb}$ & $1085 \mathrm{msh}$ & $1225 \mathrm{~m}$ \\
$975 \mathrm{sb}$ & $1010 \mathrm{~s}$ & $995 \mathrm{~m}$ \\
$915 \mathrm{svb}$ & $977 \mathrm{~s}$ & $962 \mathrm{~m}$ \\
$845 \mathrm{sb}$ & $922 \mathrm{~m}$ & $907 \mathrm{~m}$ \\
$805 \mathrm{~m}$ & $835 \mathrm{~m}$ & $82 \mathrm{mb}$ \\
$775 \mathrm{mb}$ & $785 \mathrm{w}$ & $825 \mathrm{w}$ \\
$550 \mathrm{svsb}$ & $700 \mathrm{vs}$ & $696 \mathrm{~s}$ \\
$495 \mathrm{sb}$ & $625 \mathrm{~s}$ & $623 \mathrm{~s}$ \\
$415 \mathrm{sb}$ & $570 \mathrm{~m}$ & $540 \mathrm{~m}$ \\
& $538 \mathrm{~m}$ & $518 \mathrm{~m}$ \\
& $432 \mathrm{~m}$ & $450 \mathrm{~m}$ \\
& $395 \mathrm{~s}$ & $410 \mathrm{~m}$ \\
& $330 \mathrm{~m}$ & $370 \mathrm{sb}$ \\
& $310 \mathrm{~m}$ & \\
\hline \multicolumn{2}{|l}{} \\
\hline
\end{tabular}

sussexite agree reasonably well with the results obtained by Takeuchi [5] for camsellite (szaibelyite) and sussexite and with the results of Plyusnina and Kharitonov [15] for ascharite (szaibelyite). From his spectra, Takeuchi [5] concluded that the anion in these compounds was the pyroborate ion while Plyusnina and Kharitonov, apparently being unaware of Takeuchi's earlier work, noted that the spectrum of ascharite was similar to that of $\mathrm{LaBO}_{3}$ which contains a triangular borate anion. However, the latter workers concluded tentatively that the complexity of the spectrum indicated a more complex ion than the simple triangular ion [15]. Akhamanova independently arrived at the same conclusion [14].

The structure of this anion has been reported to be a singly hydrated pyroborate group, with some uncertainty as to the exact structure [43] caused by translation. It is not clear that both borons are coordinated with three oxygen atoms. However, the spectrum clearly indicates that there is no tetrahedral boron present in the structure. From the earlier work on the pyroborates [1] it appears that the spectrum of anhydrous magnesium pyroborate becomes considerably less complex in the $\nu_{2}$ region on hydration but more complicated in the $\nu_{1}$ region. Tentative assignments are possible for many of the bands in the spectrum of szaibelyite on the basis of the spectrum of anhydrous magnesium pyroborate and the known spectrum of triangular borate groups. These are obvious and need not be specified here.

In sodium perborate the anion has been reported [44] to consist of two partly hydrated tetrahedral borate groups connected through peroxide linkages and to

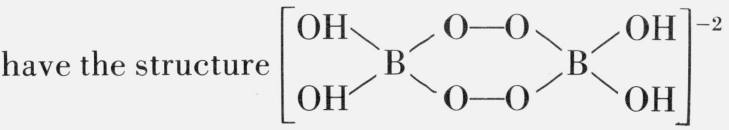

The

structural formula of sodium perborate may be written $\mathrm{Na}_{2}\left[\mathrm{BO}_{2}(\mathrm{OH})_{2}\right]_{2} \cdot 6 \mathrm{H}_{2} \mathrm{O}$. This anion is unlike any previously encountered here and its spectrum is likewise unique as shown in figure 9. In this spectrum the $3590 \mathrm{~cm}^{-1}$ band indicates some nonhydrogen bonded $\mathrm{OH}$ and the broad strong band between 3500 and $3000 \mathrm{~cm}^{-1}$ shows that much of the $\mathrm{OH}$ is hydrogen bonded. The weak $1640 \mathrm{~cm}^{-1}$ band is attributed to the bending mode of $\mathrm{H}-\mathrm{O}-\mathrm{H}$, and the medium broad bands at 1225 and $1165 \mathrm{~cm}^{-1}$ to the $\mathrm{B}-\mathrm{OH}$ bending modes plus overtones and combinations. The strong absorptions at 915 and $845 \mathrm{~cm}^{-1}$ are derived from the $\nu_{3}$ tetrahedral modes and the doublet is indicative of tetrahedral coupling as noted earlier. The strong broad band at low frequencies probably contains modes derived from $\nu_{2}$ and $\nu_{4}$ of tetrahedral units plus $\mathrm{OH}$ torsional modes. The complexity of the band indicates the presence of several overlapping bands. The spectrum for this material has been reported by Miller and Wilkins [4] with reasonably good agreement between the data.

\section{Reliability of Infrared Spectra of Hydrated Borates}

In comparing the spectra of different workers it has been noted that the agreement was not satisfactory. It is to be expected that on a given material, the same infrared bands having similar relative intensities should be obtained. Some latitude in the exact frequencies reported (i.e., a few $\mathrm{cm}^{-1}$ ) and perhaps in the detection of weak bands might be expected. For the hydrated borates it is clear that data do not agree to this extent and it is desirable to examine possible reasons for the discrepancies.

The discordance in the data must be traced to one or more of three sources; first, the materials themselves; second, the preparation techniques used to prepare the materials for study; and third, the actual measurements. Of these three sources the third can probably be dismissed as a real source of error. There is no 
evidence that any appreciable errors in band positions exist between the results obtained on different spectrometers. In fact the evidence is that the spectrometers agree within experimental error because many strong bands can be identified in spectra of various workers which agree within the frequency limits expected. It is believed, therefore, that the real causes for the discrepancies are to be attributed to variation in the materials or differences arising from techniques of preparation.

Insofar as the identity of the materials investigated is concerned, the previous reports give little information. Miller and Wilkins used chemical reagents in their studies [4]. Takeuchi [5] reports that his substances were carefully selected and were well-developed crystals of highest purity. Plyusnina and Kharitonov [15] used single crystals, but Akhamanova [14] and Moenke [7] give no details of the method used for selection of their specimens. In the present study most of the materials were of the highest purity presently available as judged by microscopic examination and x-ray powder diffraction. It must be noted, however, that neither these methods nor that of selecting natural single crystals ensures that the specimens are free of contaminants. If the contaminants should consist of other borates (all of which are strongly active in the infrared) even in small quantity, it is clear that some differences in the spectra may result. In addition to the question of purity, there remains a problem associated with the degree of crystallinity of the specimen. Most of the borates yield complex spectra containing many broad, obviously complex bands, containing unresolved structural details. Experience in this laboratory has indicated that two specimens of identical composition but differing either in degree of crystallinity or perhaps in perfection of crystallites can yield spectra which are very similar in gross appearance but remarkably different in detail. Broad featureless bands frequently show many resolvable details when the degree of crystallinity of the specimen is apparently improved. It appears most probable that discrepancies in the spectra of various workers consisting of differences in numbers of bands reported is to be attributed either to actual contamination of the specimens by other borates (or other spectrally active chemical species) or to differences in the crystallinity of the specimens.

Insofar as the specimen preparation techniques are concerned, the problem of purity is also involved but in a different manner. Here the concern is with the actual identity of the materials studied because of changes in degree of hydration or of interaction with the alkali halide windows used. The various workers used the following techniques of sample study: Miller and Wilkins and Takeuchi-mulls with hydrocarbon or fluorocarbon liquids using salt ( $\mathrm{NaCl}$ ?) plates $[4,5]$; Moenke-pressed pellet technique using vacuum formation of $\mathrm{KBr}$ pellets [7]; Akhamanova-film deposited on $\mathrm{KBr}$ plates by evaporation of isobutyl alcohol dispersing medium [14]; Plyusnina and Kharitonov - films deposited on KCl or $\mathrm{NaCl}$ plates by evaporation of isopropyl alcohol [15]; present work - films deposited on CsBr plates by evaporation of $\mathrm{CCl}_{4}$. It is well known that solids (and in particular hydrates) interact with the alkali halides and that the interaction produces changes in the spectra. Of the methods used, it would appear that the mull technique is the most preferable from the viewpoint of lessening such interactions, the film method next, and the $\mathrm{KBr}$ pellet the most objectionable. In addition to the increased probability of interaction in $\mathrm{KBr}$ pellets must be added the undesirable procedure of subjecting the hydrated borates to vacuum in the pellet forming process. Reduction in pressure might affect the state of hydration of the small quantity of hydrate present. It seems very probable that differences in positions of bands observed by different workers may be caused by shifts due to interaction with the alkali halide windows used.

In addition to the question of interaction with the alkali halide there is some uncertainty introduced by the mechanical and thermal effects of the fine grinding required to produce particles sufficiently small for infrared study. As noted earlier, the spectra for borax, a chemically pure reagent, obtained by different workers differ radically. C. J. Bowser [45] has obtained evidence showing that in $\mathrm{KBr}$ pellets, borax produces the spectrum of tincalconite, a lower hydrate. Thus the spectra for borax of Miller and Wilkins [4] and Moenke [7] which agree very well actually appear to represent tincalconite. Dehydration of borax can be understood in the $\mathrm{KBr}$ pelleting process but is hard to visualize in the mull technique, unless it occurs during grinding. Therefore, it is necessary to include the fine grinding technique among the details which might produce differences in the spectra.

It is concluded that the infrared spectra of the hydrated borates, at present, are not of acceptable reliability. The lack of reproducibility is most probably to be attributed to differences in chemical composition and degree of crystallinity and to varying interactions between the hydrated borates and the alkali halide windows. Production of definitive spectra will require systematic study of the effect of these disturbances.

\section{Identification of Borate Minerals by Infrared Spectroscopy}

H. Moenke has studied the infrared spectra of several hydrated borate minerals in a series of papers generally oriented toward differentiating among various borates [6-13]. As a result of his study he concluded that the spectral method could be used to identify hydrated borate minerals and has pointed out identifying features in the spectra of various minerals.

It is clear from the immediately preceding discussion and the comparisons between spectra made throughout this report that the present conclusions must disagree with the idea of identification by infrared methods. The fact that there is a disturbing amount of disagree- 
ment between the spectra of various workers at the present time would appear to invalidate the use of spectroscopy as a method of identification. Moreover, the spectra of most borates are so complex that it seems imperative to obtain at least a degree of understanding of the origin of the spectral bands before identification of minerals of this type is attempted on the basis of their spectra. In the case of the simpler spectra, i.e., sussexite, hambergite, etc., identification by means of infrared spectroscopy is believed to be possible. However, if such minerals were contaminated with other borates (as for example sussexite contaminated with szaibelyite) identification would be almost impossible.

\section{Conclusions}

The infrared spectra of the hydrated borates are considerably more complex than the spectra of the anhydrous analogues. The increased complexity arises from the effects of the hydration of the borate anions and hydrogen bonding between anions. The effect of the hydrogen bonding appears to produce noticeable changes in most of the borate anion fundamentals and results in complicating the spectrum throughout the frequency range $400-4000 \mathrm{~cm}^{-1}$ studied here. Thus the effects are by no means restricted to the region commonly considered to be diagnostic for $\mathrm{OH}$.

As a result of the increased number of bands the spectra are frequently poorly resolved and detailed interpretation appears to be remote. It is unlikely that any hydrated borate anion can be identified solely from its infrared spectrum. However, the previous conclusions concerning identification of three-fold and four-fold coordinated boron appear to be equally valid in the hydrated and anhydrous borates. For the hydrated compounds the conclusions are more uncertain because strong bands near $1200 \mathrm{~cm}^{-1}$ apparently arising from $\mathrm{B}-\mathrm{OH}$ bending modes fall into the region previously considered as indicative of trigonal borate groups. Any serious attempt to understand the spectra of the hydrated borates will probably require deuteration as well as boron isotope substitution.

At the present time agreement between spectra obtained by different investigators is not considered to be satisfactory. The probable causes of the disagreement are believed to originate in differences in the materials themselves or from varying degrees of interaction with the alkali halide cells used. As a result of the lack of agreement between various workers as well as the inherent complexity of the spectra it is considered that borate minerals cannot be identified at this time on the basis of their infrared spectra alone.

The author is indebted to E. R. Lippincott and R. A. Schroeder for many discussions concerning the infrared data and to G. Switzer of the Smithsonian Institution and R. C. Erd of the U.S. Geological Survey who furnished the samples which made this study possible. The very helpful comments of J. R. Clark and R. C. Erd of the U.S. Geological Survey on the structure and properties of the borate minerals were invaluable.

\section{References}

[1] C. E. Weir and R. A. Schroeder, J. Res. NBS 68A (Phys. and Chem.) No. 465 (1964).

[2] A. Perloff and S. Block, submitted to Acta Cryst.

[3] A. Mighell, A. Perloff, and S. Block, submitted to Acta Cryst.

[4] F. A. Miller and C. H. Wilkins, Anal. Chem. 24, 1253 (1952).

[5] Y. Takeuchi, Min. J. (Japan) 2, 245 (1958).

[6] H. Moenke, Jenaer Jahrbuch 1959 (II) 361.

[7] H. Moenke, Jenaer Jahrbuch 1960 (I) 191.

[8] H. Moenke, Jenaer Jahrbuch 1961 (I) 239.

[9] H. Moenke, Naturwiss. 49, 7 (1962).

[10] H. Moenke, Spectralanalyse von Mineralien und Gesteinen (Geest and Portig, Leipzig, 1962).

[11] H. Moenke, Fortschr. Min. 40, 76 (1962).

[12] H. Meixner and H. Moenke, Kali u. Steinsalz 3, 228 (1961).

[13] R. Kühn and H. Moenke, Kali u. Steinsalz 12, 399 (1963).

[14] M. V. Akhamanova, Zh. Strukt. Khim. 3, 24 (1962).

[15] I. I. Plyusnina and Yu A. Kharitonov, Zh. Strukt. Khim. 4, 506 (1963).

[16] C. L. Christ, Am. Min. 45, 334 (1960).

[17] W. H. Zachariasen, Z. Krist. 76, 289 (1931).

[18] W. H. Zachariasen, H. A. Plettinger, and M. Marezio, Acta Cryst. 16, 1144 (1963).

[19] M. Fornaseri, Period. Min. (Rome) 18, 103 (1949); 19, 159 (1950).

[20] R. L. Collin, Acta Cryst. 4, 204 (1951).

[21] V. Ross and J. O. Edwards, Am. Min. 44, 875 (1959).

[22] F. Paton and S. G. McDonald, Acta Cryst. 10, 653 (1957).

[23] D. F. Hornig and R. C. Plumb, J. Chem. Phys. 26, 637 (1957).

[24] C. R. Parkerson, Naval Ordnance Laboratory, Corona, Rept. 585 (1963b).

[25] J. R. Clark, Acta Cryst. 12, 162 (1959).

[26] C. L. Christ and J. R. Clark, Z. Krist. 114, 21 (1960).

[27] C. L. Christ, J. R. Clark, and H. T. Evans, Acta Cryst. 11, 761 (1958).

[28] A. Ashirov, I. M. Rumanova, and N. V. Belov, Dokl. Akad. Nauk SSR 143, 331 (1962).

[29] I. M. Rumanova and A. Ashirov, Kristallografiya, 8, 517 (1963).

[30] I. M. Rumanova and A. Ashirov, Kristallografiya, 8, 828 (1963).

[31] J. R. Clark, D. E. Appleman, and C. L. Christ, J. Inorg. Nucl. Chem. 26, 73 (1964).

[32] C. R. Parkerson, Naval Ordnance Laboratory, Corona, Rept. 583 (1963a).

[33] W. T. Schaller, A. C. Vlisidis, and M. E. Mrose, Am. Min. 50, 629 (1965).

[34] J. R. Clark, Am. Min. 49, 1549 (1964).

[35] V. V. Kondrat'eva, Zap. Vses. Min. Obshch. 88, 330 (1959).

[36] See Dana's System of Mineralogy, C. Palache, H. Berman, and C. Frondel, Vol. II, p. 343 (John Wiley \& Sons, Inc., New York, N.Y. 1951).

[37] H. M. Kurbanov, I. M. Rumanova, and N. V. Belov, Dokl. Akad. Nauk. SSR 152, 1100 (1963).

[38] J. R. Clark and D. E. Appleman, Sci. 145, 1295 (1964).

[39] N. Morimoto, Min. J. (Japan) 2, 1 (1956).

[40] M. Marezio, A. A. Plettinger, and W. H. Zachariasen, Acta Cryst. 16, 975 (1963).

[41] J. R. Clark, Am. Min. 45, 1087 (1960); J. R. Clark and C. L. Christ, Am. Min. 44, 1150 (1959).

[42] C. E. Weir and E. R. Lippincott, J. Res. NBS 65A (Phys. and Chem.) No. 3, 173 (1961).

[43] C. P'eng, C. Y. Su, and P. H. Chang, Sci. Sinica (Peking) 12, 1761 (1963).

[44] A. Hansson, Acta. Chem. Scan. 15, 934 (1961).

[45] C. J. Bowser, submitted to Am. Min.

(Paper 70A2-391) 